\title{
Cognitive Biases and Religious Belief: A Path Model Replication in the Czech Republic and Slovakia With a Focus on Anthropomorphism
}

Social Psychological and Personality Science 2020, Vol. II (I) 97-106 (C) The Author(s) 2019 (c) (i) (5)

Article reuse guidelines: sagepub.com/journals-permissions DOI: $10.1177 / 1948550619841629$ journals.sagepub.com/home/spp

@SAGE

\author{
Aiyana K. Willard ${ }^{1,2,3}$, Lubomír Cingl ${ }^{4}$, and Ara Norenzayan ${ }^{5}$
}

\begin{abstract}
We examined cognitive biases that underlie individual differences in supernatural beliefs in nationally representative samples from the Czech Republic and Slovakia (total $N=2,022$ ). These countries were chosen because of their differing levels of religious belief despite their cultural similarity. Replicating a previous study with North American samples, we found that anthropomorphism was unrelated to belief in God but was consistently related to paranormal beliefs. Living in a highly religious area was related to a lower tendency to anthropomorphize. We examined this relationship further to find that anthropomorphism was related to belief in God for nonreligious participants, was inversely related to belief in God among religious Slovaks, and not related for religious Czechs. These findings suggest that anthropomorphism predicts belief in God for people who are unaffiliated, but this relationship disappears or is reversed for religious believers participating in a Christian religious tradition.
\end{abstract}

\section{Keywords}

cognitive biases, anthropomorphism, religion, paranormal beliefs, replication

Religion is a central part of the identity and social life of the great majority of people around the world (Hackett, et al., 2015). As such, research on the psychological roots of religious belief has proliferated over the last several decades. Recently, this growth has spurred calls for scrutinizing the conclusions of psychology of religion research just as for many other core topics within psychology (e.g., Nosek et al., 2015). Work has begun that evaluates meta-analytic conclusions (e.g., Shariff, Willard, Anderson, \& Norenzayan, 2016; van Elk et al., 2015), replication efforts (e.g., Sanchez, Sundermeier, Gray, \& Calin-Jageman, 2017), and the cross-cultural generalizability of findings (e.g., Gervais et al., 2018; Purzycki et al., 2016). Still, rigorous testing of the evidentiary value of findings remains relatively rare in the psychology and cognitive science of religion, with many of the core findings remaining unreplicated.

With this in mind, this article has two aims: (1) to replicate the relationship between cognitive biases and different types of supernatural beliefs found in Willard and Norenzayan (2013) in a new sample and (2) to further examine some of the unexpected findings from that paper, namely, the surprising lack of a relationship between anthropomorphism and belief in God, and the inverse relationship between living in a religious area and anthropomorphism.

\section{The Cognitive Foundations of Religious Belief}

We focus on one of the key insights from psychological research into the origins of religious belief. This is the proposal that the roots of religious belief might be found in interrelated cognitive biases, specifically, mind-body dualism, teleology, and anthropomorphism (Atran \& Norenzayan, 2004; Barrett, 2007; Boyer, 2001). Mind-body dualism is the intuitive tendency to see the mind as separate from, and irreducible to, the body (Bloom, 2005; Damasio, 1994; Jack et al., 2013). Teleology is the tendency to see natural objects as though they are

\footnotetext{
'Centre for Culture and Evolution, Brunel University London, United Kingdom

${ }^{2}$ Department of Life Sciences, College of Health and Life Sciences, Brunel University London, Middlesex, United Kingdom

${ }^{3}$ School of Anthropology and Museum Ethnography, University of Oxford, Oxford, United Kingdom

${ }^{4}$ Department of Economics, Faculty of Economics, University of Economics, Prague, Czech Republic

${ }^{5}$ Department of Psychology, University of British Columbia, Vancouver, British Columbia, Canada
}

\section{Corresponding Author:}

Aiyana K. Willard, Centre for Culture and Evolution, Brunel University London, Uxbridge, UB8 3PH, United Kingdom.

Email: aiyana.willard@brunel.ac.uk 
artifacts and intentionally made for a purpose (Kelemen, 1999; 2004). Anthropomorphism is the tendency to see nonhuman objects and entities as having humanlike traits, particularly as pertaining to human psychological states such as consciousness, emotions, and memory (Epley, 2014; Waytz, Cacioppo, \& Epley, 2010; Waytz, Morewedge et al., 2010). These core cognitive biases, which are rooted in the everyday workings of human minds, may partly explain why mental representations of supernatural agents are found so frequently across societies.

Research has begun to look at exactly how these cognitive biases work together to prompt religious and other types of supernatural beliefs (e.g., Andersen, 2017; Banerjee \& Bloom, 2014; Järnefelt, Canfield, \& Kelemen, 2015; Lindeman, Svedholm-Häkkinen, \& Lipsanen, 2015). Of particular relevance to this article, Willard and Norenzayan (2013; henceforth W\&N) ran path models connecting mentalizing tendencies to religious, paranormal, and life's purpose beliefs through these three cognitive biases-mind-body dualism, teleology, and anthropomorphism. The two samples W\&N used for the analyses were drawn from North American populations and thus the generalizability of these findings outside of this population remains an open question. To expand these findings, we examine these path models in two new samples drawn from different populations in Central Europe with similar cultural histories but differing religiosity levels. Moreover, some of the key findings in $\mathrm{W} \& \mathrm{~N}$ were unexpected - not derived from a priori predictions based on existing theories. Therefore, we focus our efforts on this article particularly on these findings that were not originally predicted from theory to examine their reliability in these new samples.

\section{Anthropomorphism and Religion}

One key unexpected result from W\&N's models was a lack of a relationship between anthropomorphism and belief in God and a modest but negative relationship between living in a highly religious area and anthropomorphism. These effects are notable because anthropomorphism has been a central focus of the cognitive science of religion (e.g., Barrett, 2004; Guthrie, 1993) and an influential cognitive hypothesis about the origin of supernatural belief dating all the way back to Hume (1779/1981). One line of theorizing in the cognitive science of religion suggests that humans possess an overzealous tendency to project humanlike traits unto the world at large, sometimes called hyperactive agency detection. This has led to the propensity to perceive supernatural agents everywhere and forms a cognitive foundation for religion (Barrett, 2000; Barrett \& Lanman, 2008). Although some work has criticized the idea of anthropomorphism as based in a hyperactive agency detection (Andersen, 2017; Bulbulia, 2004; Lisdorf, 2007), anthropomorphism itself remains central to theories of the origin of religious beliefs.

An alternate view within the cognitive science of religion is that anthropomorphism is deployed because it is inferentially rich and facilitates explanation in situations when other causal frameworks are lacking (Andersen, 2017; Boyer, 2001;
Epley, Akalis, Waytz, \& Cacioppo, 2008; Willard, 2017). Phenomena like weather patterns, or even life events, are often causally opaque; they are not easily understood using our intuitive processes of causal reasoning. Projecting minds, either directly or through a deity, onto these events gives some sense of understanding and feeling of control over these otherwise unknowable systems (Kay, Gaucher, McGregor, \& Nash, 2010; Kay, Whitson, Gaucher, \& Galinsky, 2009; Laurin \& Kay, 2017). This latter perspective on anthropomorphism conceptualizes it as the motivated use of mental state reasoning to make sense of the world (Epley, Waytz, Akalis, \& Cacioppo, 2008; Waytz, Morewedge et al., 2010). In this conception, people use humanlike mental states as explanations of otherwise unexplainable actions, behaviors, or events, such as a sudden, devastating storm.

When we apply this perspective of motivated reasoning to the Christian God, it suggests that belief in an all-powerful anthropomorphic God that controls the world might remove the motivation to anthropomorphize other parts of the world. For example, if the explanation for a devastating storm can be explained by the will of God, then there is no need to attribute anthropomorphic traits to the storm directly. Still, the lack of a relationship between anthropomorphism and belief in God in W\&N does not clearly support the idea that belief in God removes the need for general anthropomorphism. If this were the case, we should expect this relationship to be negative, not null. People who believe in God should be less likely to anthropomorphize the world at large. The null effect suggests that anthropomorphism simply is not related to this specific belief.

Additionally, this null finding does not undermine the idea that anthropomorphism is a foundational cognitive bias underlying religious belief. $\mathrm{W} \& \mathrm{~N}$ also found anthropomorphism was in fact positively related to paranormal beliefs (also see Elk, 2013; Willard \& Norenzayan, 2017) and more weakly and inconsistently to belief in life's purpose. This suggests that even if anthropomorphism is not related to belief in God, it may still be an important predictor of other supernatural beliefs and an underlying feature of why humans have supernatural beliefs more generally.

Beyond cognitive biases, religion is also clearly influenced by cultural learning (Gervais, Willard, Norenzayan, \& Henrich, 2011). As cultural learners, people adopt specific religious beliefs from their families and communities. Although cognitive biases serve as a template for religious beliefs and explain why there is a human propensity for religious belief, it is cultural learning that explains why people believe in the specific set of beliefs that make up a specific religious tradition (e.g. Christianity) and not another (Gervais \& Henrich, 2010; Willard \& Cingl, 2017).

W\&N assessed the contribution of cultural learning to religious belief by measuring the prevalence of church membership in the participants' geographic region and found that it has a small but reliable effect belief in God. W\&N also found an unpredicted negative relationship between the rate of church membership in each participant's local area and anthropomorphism. This suggests that a Christian cultural context 


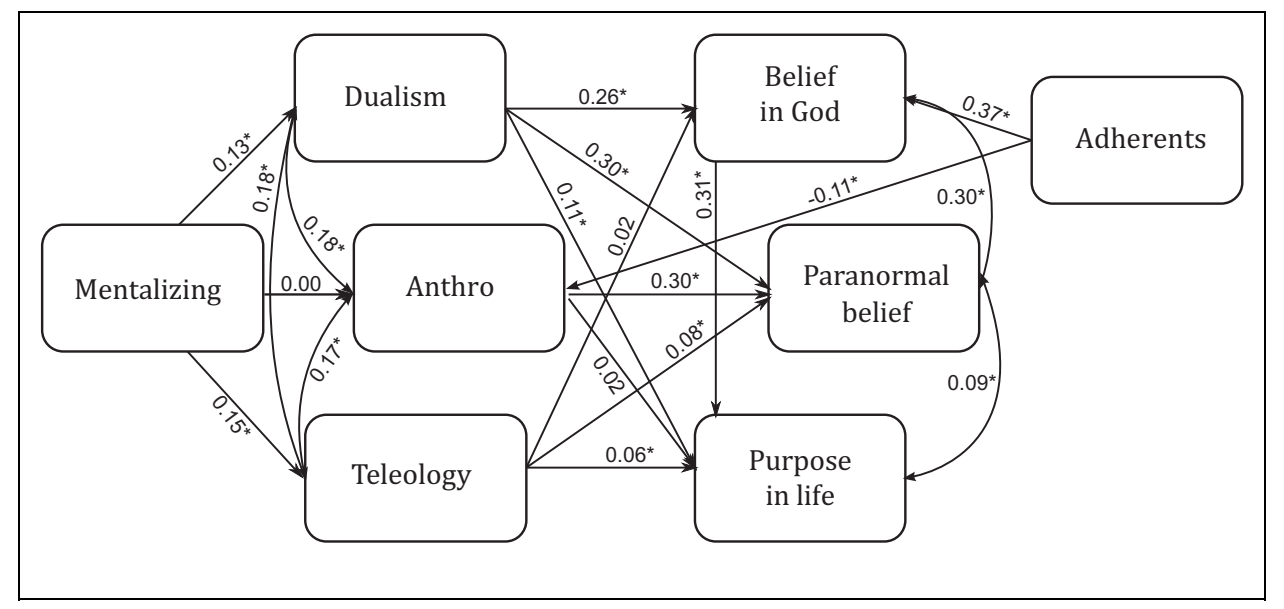

Figure I. The path model across both countries. Yuan-Bentler $\chi^{2}(9, N=2,012)=100.32, p<.001 ; \mathrm{CFI}=0.95 ; \mathrm{RMSEA}=0.07,90 \% \mathrm{Cl}[0.06$, 0.09]. This is a modest fit. When an additional relationship is included between mentalizing and purpose $(\lambda=.16, z=6.86, p<.00 \mathrm{I})$, it improves the fit: Yuan-Bentler $\chi^{2}(8, N=2,012)=58.48, p<.001$; CFI $=0.97 ;$ RMSEA $=0.06,90 \% \mathrm{Cl}[0.05,0.07] .{ }^{*} p<.05$.

suppresses anthropomorphism. Anthropomorphizing the world is counternormative in a Christian context, which may explain this negative relationship. Together, these findings suggest that the cultural context of belief, as well as the type of supernatural belief itself (i.e., God or paranormal beliefs), can change how anthropomorphism relates to a supernatural belief.

To investigate these relationships more closely, we sought to replicate and extend the findings of W\&N using nationally representative data collected in the Czech Republic and Slovakia. These two countries have similar histories, cultures, languages, and geographic location but strikingly different levels of religious commitment. The Czech Republic is currently one of the least religious countries in Europe, with only $18 \%$ of the population claiming to be religious. Slovakia on the other hand has a Christian religious majority of $76 \%$ (Willard \& Cingl, 2017). The diversity in belief across these two countries gives us more variance in the religiosity of the participants' local area. Specifically, there is a much larger proportion of people living in largely nonreligious areas. This increased variance should make a relationship between anthropomorphism and living in a religious area easier to detect, if one exists.

The large difference in religiosity also allows us to test if the null relationship between anthropomorphism and belief in God is about the religious context or the belief in a deity more specifically. If anthropomorphism simply does not predict belief in deities, then this effect should be found among both the religious and the nonreligious (i.e., people who do not affiliate with a religious tradition) who still believe in a God. If, on the other hand, Christianity is suppressing the tendency to anthropomorphize, then anthropomorphism should still predict God beliefs among the nonreligious.

\section{Current Research}

We focus our replication efforts on the final model from W\&N (figure 4 in that paper), which included district-level church affiliation (how many people hold active membership in a church in each participants' local district) as the measure of adherents. Specifically, we wanted to see whether we could replicate the finding that cultural exposure to religion in one's community was related to higher levels of belief in God but lower levels of anthropomorphism in a sample with greater variance in belief. We ran the model a second time using country as a proxy for adherents to test for country-level differences in these effects as an additional test of the robustness of these effects.

Additionally, we took a closer look at the relationship between anthropomorphism and belief in God by examining the differences between religious and nonreligious participants within each country. The relationship between anthropomorphism and other supernatural beliefs in W\&N leaves open the possibility that this null effect between anthropomorphism and belief in God was specific to religious participants (in this case, Christians) and may not be about belief in a deity more generally. If it is the cultural context of Christian belief that suppresses the tendency to anthropomorphize rather than the belief in any sort of God, then we should still find a relationship between anthropomorphism and belief in God among nonreligious participants. Furthermore, we should find a stronger relationship in the less religious country (Czech Republic) than in the more religious one (Slovakia) because the cultural influence of Christianity will be weaker in the less religious country.

\section{Method}

Data from both samples were collected as self-report questionnaires on behalf of the researchers by the Czech branch of Ipsos market research firm and has been used in a previous study (Willard \& Cing1, 2017). The questionnaire was translated into Czech and Slovak by a bilingual researcher familiar with the theories and scales aided by a professional translator and back translated into English. Demographics were collected by Ipsos separately. Quality checks were conducted by Ipsos and no participants were excluded by the researchers. 


\section{Participants}

Both the Czech $(N=1,010)$ and Slovak $(N=1,012)$ samples were demographically and geographically representative and consist of $50 \%$ females with a mean age of 40.6 years $(S D=$ $13.23)$ and 41.3 years $(S D=13.22)$, respectively. A sample size of 1,000 per country was similar to the sample size of $\mathrm{W} \& \mathrm{~N}(N=920)$. Power analysis for this type of structural equation model is not reliable, but our sample is well above any recommended minimum sample (Wolf, Harrington, Clark, \& Miller, 2013).

\section{Materials}

Measures. All measures except adherents (see below) were the same as those used in W\&N. The adherents measure used here was collected as rates of church membership in each participant's district collected from census data. W\&N's measure was attendance reported by churches in each participant's county.

Anthropomorphism. The individual differences in anthropomorphism quotient (IDAQ) was used (Waytz, Cacioppo et al., 2010; To what extent does the ocean have consciousness? To what extent does the average computer have a mind of its own? $\alpha=$.87).

Dualism. Stanovich's (1989) Dualism Scale was used (e.g., The mind is not part of the brain, but it affects the brain; Mental processes are the result of activity in my nervous system; $\alpha=.77$ ).

Teleology. We used a series of statements created by Kelemen and Rosset (2009) with levels of agreement on a 7-point Likert-type scale (e.g., Earthworms tunnel underground to aerate the soil; The sun makes light so that plants can photosynthesize; $\alpha=.92$ ).

Mentalizing. The Empathy Quotient (EQ) to measure mentalizing as used (Baron-Cohen \& Wheelwright, 2004; e.g., I often find it difficult to judge if someone is rude or polite; I am good at predicting how someone will feel; $\alpha=.87$ ).

Belief in God. Belief in God was measured with a three-question scale (I believe in God; I believe in a divine being who is involved in my life; There is no God or higher power in the universe; $\alpha=.71)$.

Paranormal belief. The Revised Paranormal Belief Scale was used (Tobacyk, 2004). The religiosity and mystical animals subscales were removed because of overlapping with the other belief measures and cultural specificity, respectively (Some individuals are able to levitate [lift] objects through mental forces; Astrology is a way to accurately predict the future; $\alpha=.94)$.

Life's purpose. Life's purpose was measured using a threequestion scale (Things in my life happen for a reason; There is a discernible purpose to the events of my life; Many things that happen to me are random or coincidental; $\alpha=.69$ ).

Adherents. The proportion of adherents by district measure came from the Czech and Slovak census data (self-report church membership). This was matched to each participant's local district.

We additionally asked participants if they considered themselves religious, spiritual but not religious, or not religious (forced-choice answer). We transformed this variable to religious and nonreligious (combining "spiritual but not religious" and "not religious") for the final analysis.

Materials, ${ }^{1}$ data, and analysis scripts are available at https:// osf.io/p5k6w/?view_only=557cfa6af6ce44bbb58e6923 $\mathrm{da} 08 \mathrm{c} 786$.

\section{Results}

\section{Population Differences in Belief}

The Slovak sample had higher ratings of belief in God than the Czech sample (all scales 1-7; Czech: $M=3.65, S D=1.48$; Slovak: $M=4.73, S D=1.58 ; d=0.71,95 \%$ CI $[0.61$, $0.80])$. Conversely, average anthropomorphism was higher in the Czech sample $(M=2.87, S D=1.15)$ than Slovak $(M=$ $2.60, S D=1.17 ; d=-0.23,95 \%$ CI $[-0.32,-0.15])$. Both samples had similar ratings of paranormal beliefs (Czech: $M$ $=3.32, S D=1.16$; Slovak: $M=3.24, S D=1.13 ; d=$ $-0.07,95 \%$ CI $[-0.16,0.02])$ and life's purpose (Czech: $M$ $=4.30, S D=0.95$; Slovak: $M=4.36, S D=0.93 ; d=0.07$, $95 \%$ CI $[-0.02,0.16])$.

\section{Replicating Willard and Norenzayan's Path Model}

The model was fit with the lavaan package in R (Rosseel, $2012)^{2}$ using a full information maximum likelihood (FIML) to deal with a small amount of missing data (Figure 1). The model shows only modest fit, Yuan-Bentler $\chi^{2}(9, N=2,022)$ $=102.43 p<.001 ; \mathrm{CFI}=0.94 ;$ RMSEA $=0.0890 \% \mathrm{CI}$ $[0.06,0.09]$; Figure 1. After looking for additional unspecified variance, we found an unspecified relationship between mentalizing and purpose and added a correlation between the errors of these variables $(\lambda=.16,95 \%$ CI $[0.11,0.20], p<.001)$. Including this path brings us to a more acceptable level of fit, Yuan-Bentler $\chi^{2}(8, N=2,022)=64.20, p<.001$; CFI $=$ 0.97 ; RMSEA $=0.06,90 \%$ CI $[0.05,0.08]$.

The $\chi^{2}$ value remains significant suggesting our model fits less well than the model in the original paper. The $\chi^{2}$ test of fit is less likely to fit with increases in samples size (the sample size is doubled here), making it a highly conservative test of fit and the model presented here is a good fit by both the RMSEA and the CFI (Hu \& Bentler, 1999; Kline, 2011). We do find marginally better fit if we include a path directly from anthropomorphism to belief in God, $\chi^{2}(1)=4.04, p=.04$, but this path is exceedingly small $(\lambda=.04,95 \%$ CI $[0.00,0.08]$, $p=.05)$. 
Table I. Regression Equations in Structural Equation Models.

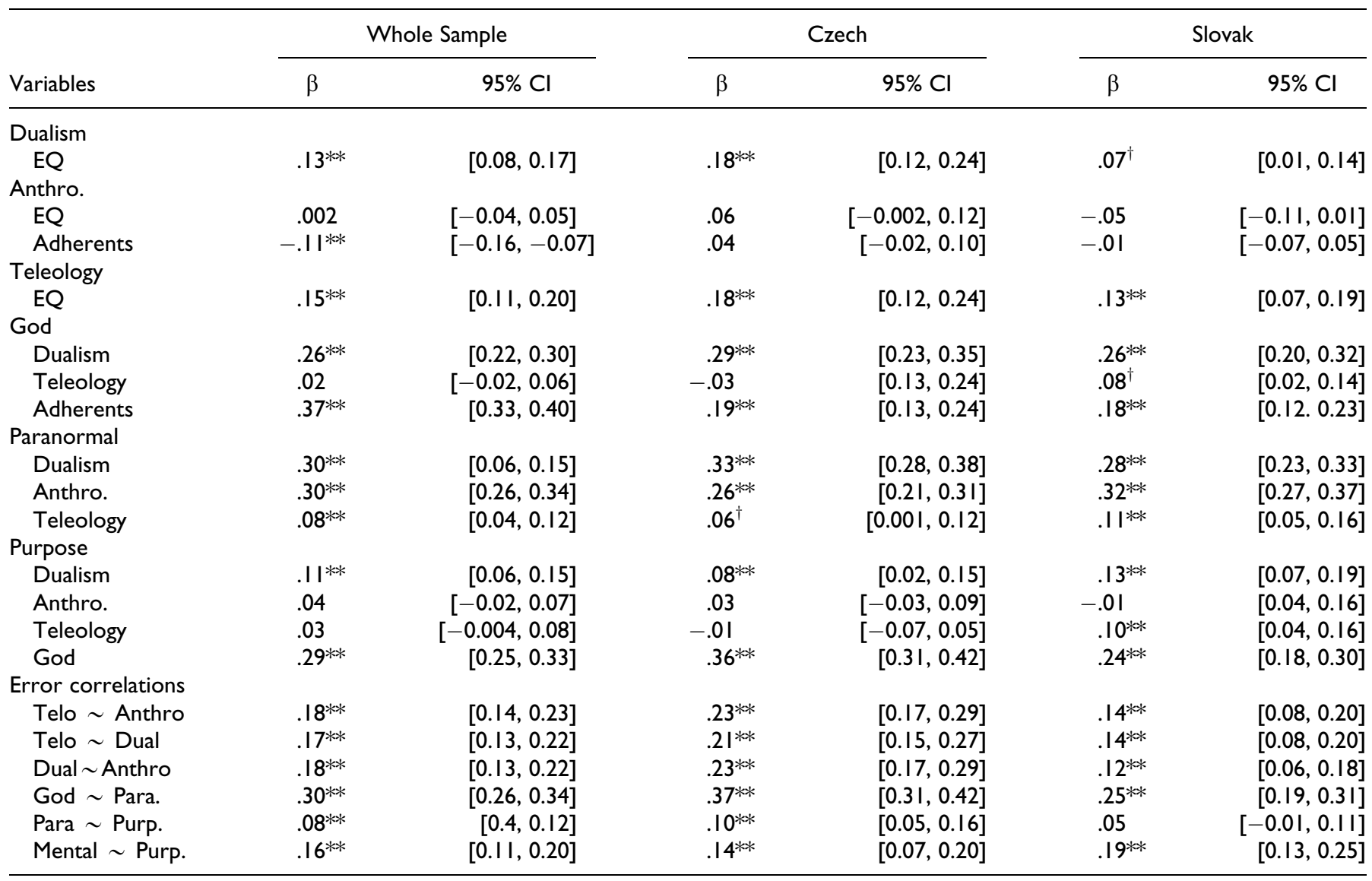

Note. Dependent variables in italic. Estimates are $\beta \mathrm{s}$, that is, standardized coefficients from ordinary least squares (OLS) estimation; $95 \%$ confidence intervals in square brackets. Czech and Slovak sets show unconstrained paths (paths are allowed to differ between groups).

${ }^{\dagger} p<.05 . * * p .001$.

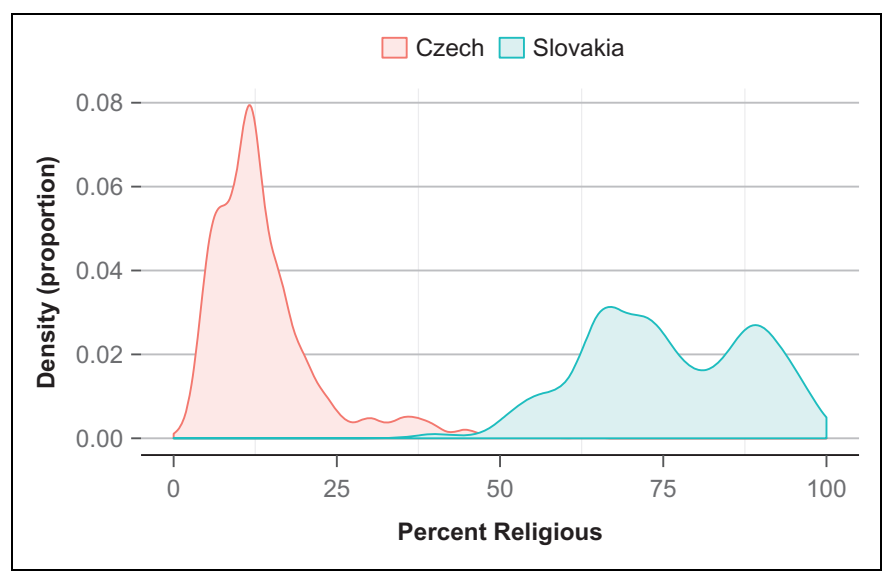

Figure 2. Density of participants' local districts by percentage people who are religiously affiliated in that district (adherents).

All coefficients and their confidence intervals can be found in Table 1. Significance was determined by confidence intervals. Exact $p$ values were not included because the vast majority of coefficients were significant at a $p<.001$ level. Coefficients that did not meet this level of significance are clearly marked.
The finding that living in an area with high religious affiliation is related to higher religiosity, but lower anthropomorphism was replicated in this sample. This effect was also found by replacing the affiliation measure with a dummy code representing country $($ Czech $=0$, Slovakia $=$ 1) with a similar level of fit, Yuan-Bentler $\chi^{2}(8, N=$ $2,022)=59.59, p<.001 ; \mathrm{CFI}=0.97$; RMSEA $=0.06$, $90 \%$ CI $[0.04,0.07]$. This is unsurprising given the distribution of our adherents measure within these two countries (Figure 2). Participants living in Slovakia are more likely to believe in $\operatorname{God}(\lambda=.33, z=16.64, p<.001)$ and less likely to anthropomorphize $(\lambda=-.12, z=-5.50, p<$ .001) when compared to people in the Czech Republic.

\section{Within Country Models}

We ran the Czech and Slovak samples as a two-group model to see if these effects are found within the countries independently (Figure 3). Similar levels of fit were found when all paths are constrained to be equal in both groups, Yuan-Bentler $\chi^{2}(16$, $N=2,022)=87.40, p<.001 ; \mathrm{CFI}=0.94$; RMSEA $=0.06$, $90 \%$ CI $[0.05,0.07]$, and when paths were allowed to differ, Yuan-Bentler $\chi^{2}(30, N=2,022)=122.57, p<.001$; 


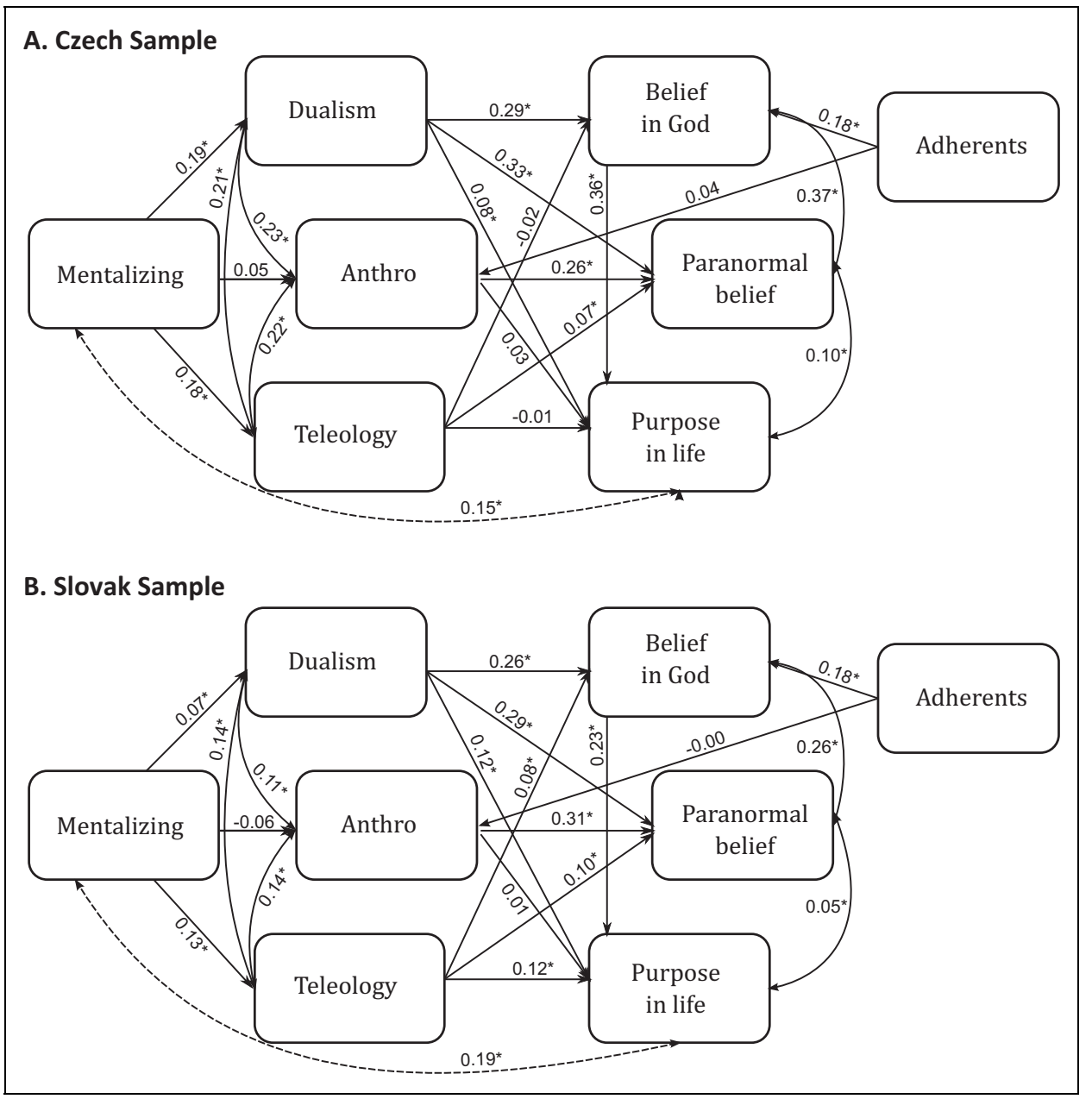

Figure 3. Models run in country samples separately, including the additional direct relationship between mentalizing and purpose in life (dotted line). $*_{p}<.05$.

$\mathrm{CFI}=0.96 ; \mathrm{RMSEA}=0.07,90 \% \mathrm{CI}[0.05,0.08]$. The positive relationship between adherents and belief in God was replicated in both models but not the negative effect on anthropomorphism. This may be due to the lack of within-country variance for the adherents measure (see Figure 2; shows unconstrained paths in both groups). If we add in the path between anthropomorphism and belief in God, we find no increase in fit for Slovakia, $\chi^{2}(1)=0.73, p=.40 ; \lambda=-.03,95 \%$ CI $[-0.09$, $0.04], p=.40$, but a significant increase in fit in the Czech Republic, $\chi^{2}(1)=12.56, p<.001 ; \lambda=.12,95 \%$ CI $[0.05$, $0.18], p<.001$. This effect, and potential reasons for it in the Czech sample, is broken down further in the following section. Correlations and standard deviations can be found in Tables 2 and 3.

\section{Anthropomorphism}

To examine these findings further, we regressed anthropomorphism on belief in God in each sample independently. Again, we found a significant relationship between anthropomorphism and belief in God in the Czech sample but not in the Slovak sample (Table 4). This relationship was broken down further to investigate religious and nonreligious participants separately. ${ }^{3}$ Participants were split into religious and nonreligious groups based on self-categorization. We found that those who self-described themselves as nonreligious (including spiritual but not religious) in the Czech Republic drove the overall relationship between anthropomorphism and belief in God. There was no effect for religious participants. In the Slovak sample, there was a negative relationship for religious participants and a positive relationship for nonreligious participants. These opposing effects created the lack of relationship in the sample as a whole.

\section{Discussion}

The path model from W\&N was, for the most part, replicated in this sample. We did find some differences, most notably the additional direct relationship between mentalizing and life's purpose. We had no a priori predictions why this might be the case, so we caution against any strong interpretations of this effect without further research. Other differences are expanded upon below. 
Table 2. Correlation Table for the Whole Sample (Both Countries).

\begin{tabular}{|c|c|c|c|c|c|c|c|c|}
\hline Variables & $\mathrm{EQ}$ & Dual. & Anthro & Teleo. & God & Para. & Purp. & Adher. \\
\hline EQ & $(0.67)$ & & & & & & & \\
\hline Dualism & $.13^{* *}$ & $(0.85)$ & & & & & & \\
\hline Teleology & $.15^{* *}$ & $.19 * *$ & $.18^{* *}$ & $(1.24)$ & & & & \\
\hline God & $.17^{* *}$ & $.29 * *$ & $.05^{\dagger}$ & $.08 * *$ & $(1.62)$ & & & \\
\hline Paranormal & $.10 * *$ & $.36 * *$ & $.37 * *$ & $.19 * *$ & $.33 * *$ & $(1.15)$ & & \\
\hline Country (Slovakia) & $.06 *$ & .04 & $-.12^{* *}$ & .03 & $.33 * *$ & -.04 & .04 & $0.94^{* *}$ \\
\hline
\end{tabular}

Note. Standard deviations are on the diagonal.

${ }^{\dagger} p<.05 . * p<.01 . * * p<.001$.

Table 3. Correlations Within Each Country (Bottom Is Czech Republic, Top Is Slovakia).

\begin{tabular}{lcccccccc}
\hline Variables & EQ & Dual. & Anthro & Teleo. & God & Para. & Purp. \\
\hline EQ & $(0.65)(0.69)$ & $.07^{\dagger}$ & -.05 & $.13^{* *}$ & $.17^{* *}$ & $.08^{\dagger}$ & $.24^{* *}$ \\
Dualism & $.18^{* *}$ & $(0.87)(0.82)$ & $.12^{* *}$ & $.15^{* *}$ & $.30^{* *}$ & $.33^{* *}$ & $.07^{\dagger}$ \\
Anthropom. & .06 & $.23^{* *}$ & $(1.17)(1.14)$ & $.13^{* *}$ & .02 & $.35^{* *}$ & .02 & $.12^{* *}$ \\
Teleology & $.17^{* *}$ & $.23^{* *}$ & $.23^{* *}$ & $(1.24)(1.24)$ & $.12^{* *}$ & $.19^{* *}$ & .01 \\
God & $.15^{* *}$ & $.28^{* *}$ & $.18^{* *}$ & .03 & $(1.58)(1.48)$ & $.30^{* *}$ & $.32^{* *}$ & .02 \\
Paranormal & $.13^{* *}$ & $.40^{* *}$ & $.39^{* *}$ & $.20^{* *}$ & $.44^{* *}$ & $(1.14)(1.16)$ & $.18^{* *}$ \\
Purpose & $.19^{* *}$ & $.22^{* *}$ & $.12^{* *}$ & .05 & $.41^{* *}$ & $.30^{* *}$ & $(0.92)(0.95)$ & .01 \\
Adherents & $-.07^{\dagger}$ & .03 & 0.04 & -.05 & $.19^{* *}$ & .00 & .04 & $(12.77)(8.87)$ \\
\hline
\end{tabular}

Note. Bottom triangle is the Czech Republic and top triangle is Slovakia. The bottom number on the diagonal is the standard deviation for the Czech Republic, and the top number is the standard deviation for Slovakia.

${ }^{\dagger} p<.05 . * p<.01 . * * p<.001$.

\section{Mentalizing}

Similar to the student sample - but not the adult sample - in $\mathrm{W} \& \mathrm{~N}$, we found no relationship between mentalizing and anthropomorphism in our path models. Given this finding in 3 of the 4 samples in which this model has been run, we suggest that there is currently no strong evidence of a direct link between mentalizing and anthropomorphism with the currently used measures. In contrast, the relationships between mentalizing and both dualism and teleology are small but robust across all four samples.

Other evidence has suggested the direct link between mentalizing and supernatural belief is small (Lindeman et al., 2015; Maij et al., 2017; Vonk \& Pitzen, 2017). The indirectness of this relationship may explain why. If mentalizing is primarily related to these beliefs through intervening cognitive biases such as dualism and teleology, then the direct relationship may not emerge as reliably. Nevertheless, at its most basic, the ability to reason about mental states should be a core process involved in attributing mental states to nonhuman entities and objects. Given this, an absence of a positive relationship between mentalizing and anthropomorphism is an interesting puzzle for future research. One possibility is that mentalizing, measured as the ability to use mental states appropriately to understand other people, and anthropomorphism, measured as the promiscuous projection of mental states to the world at large, are more distinct from each other than previously thought (see Willard \& Norenzayan, 2017). Overall, the EQ has its limitations, as it conflates accuracy and propensity in mental state reasoning (the latter being the most relevant aspect of mentalizing as it relates to supernatural belief). This in itself may attenuate some of these effects, making them smaller than they actually are.

Beyond W\&N, other research has suggested different cognitive tendencies are related to religious belief using similar methods. Lindeman, Svedholm-Häkkinen, and Lipsanen et al. (2015) paired mentalizing with ontological confusion - or the tendency to confuse attributes of core knowledge, such as attributing biological or psychological states to inanimate objects - to predict different types of supernatural beliefs. This construct is similar to what Atran and Norenzayan (2004) refer to as "ontological violations" that are an important feature of supernatural beliefs. Lindeman and colleagues' work uses statements with misattributed causes, similar to the methods employed by Kelemen's (2009) studies on teleological reasoning but extends this work beyond purpose-based statements to include anthropomorphic traits. Lindeman et al. (2015) found a consistent direct relationship between mentalizing and supernatural belief, even with the inclusion of ontological confusion. Across all their models, a small positive relationship of mentalizing remained, suggesting that ontological confusion is a 


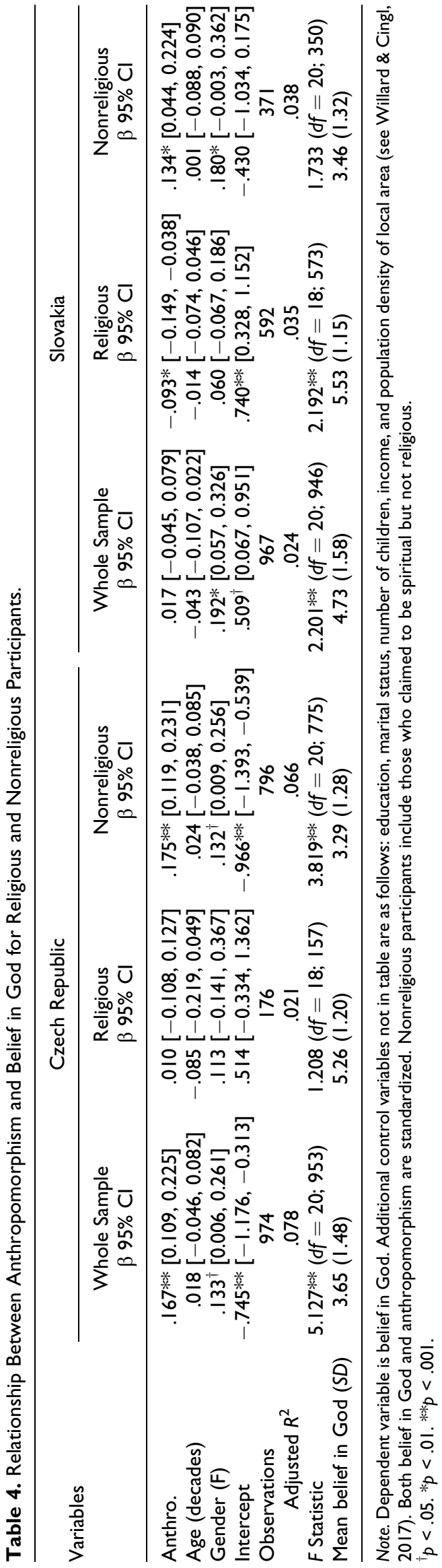

distinct construct and does not account for the contribution of mentalizing.

\section{Anthropomorphism}

The link between anthropomorphism and paranormal beliefs was replicated, supporting theories that give anthropomorphism a central role in supernatural beliefs. The relationship between anthropomorphism and belief in God is more complex. The two hypotheses put forward in the introduction suggest that (1) Christians, and people living among Christians, are less likely to anthropomorphize generally because it is counternormative within a Christian belief system and (2) Christian belief in an anthropomorphic God gives people a cognitive framework with which to explain the unexplained behavior of nature, animals, and objects, replacing the need to give them humanlike psychological qualities directly.

The finding that living in a highly religious area was related to reduced anthropomorphism is more compatible with the counternormative explanation, but the negative effect of being religious on anthropomorphism among Slovak believers does provide some evidence for an anthropomorphic God as replacing the need for general anthropomorphism. These hypotheses are not mutually exclusive and both may apply. This negative effect of anthropomorphism on belief in God was not found among the religious in the Czech sample. This may be due to the impact of being religious in a nonreligious and more generally anthropomorphizing society or to random fluctuation due to the smaller sample. Further research is needed to increase confidence in these effects.

Both of these explanations lend themselves to the perspective of anthropomorphism as motivated reasoning and the use of agency to make sense of the world because it is inferentially rich (see Boyer, 2001). This view is consistent with views of magic and a plethora of other supernatural beliefs studied within anthropology, which further suggests people engage in supernatural causal explanations even when they understand the natural causal pathways to attain more ultimate questions of meaning and personal relevance (Evans-Pritchard, 1937; Legare \& Gelman, 2008; Malinowski, 1954).

Recent research that has looked at anthropomorphism among Indian Hindus has found a similar lack of relationship between anthropomorphism and belief in God (Baimel, McNamara, Purzycki, Willard \& Norenzayan, n.d.). Although this work did not look at the density of religious believers in a given area, it does suggest that this lack of relationship may not be limited to Christians. Regardless, these results suggest that the cultural prevalence of a supernatural belief itself can moderate the effects of the cognitive biases underlying supernatural beliefs.

\section{Conclusion}

In two high-powered, nationally representative samples in the Czech and the Slovak Republics that vary on religiosity levels, we replicate and extend previous findings connecting 
individual differences in cognitive biases to various types of supernatural beliefs. We also report new evidence that the cultural milieu matters in how cognitive biases, specifically anthropomorphism, relate to supernatural beliefs. We conclude that both cognitive tendencies and the cultural context, and their interactions, are important to get a complete picture of how supernatural beliefs are formed.

\section{Declaration of Conflicting Interests}

The author(s) declared no potential conflicts of interest with respect to the research, authorship, and/or publication of this article.

\section{Funding}

The author(s) disclosed receipt of the following financial support for the research, authorship, and/or publication of this article: This research was funded by SSHRC Insight Grant (435-2014-0456) "The Cognitive Origins of Religious Belief and Disbelief" to A. N. A.W. received financial support from the Templeton World Charity Foundation (TWCF0164). L.C. received financial support from research grand GA15-03488S from the Grant Agency for the Czech Republic (GACR).

\section{Notes}

1. Addition variables were collected beyond what is presented here. They were not included as they are not relevant to the questions posed by this article and were not used in the previous analyses this article attempts to replicate. These additional variables are reported at the Open Science Framework (OSF) link.

2. The W\&N models were fit using the EQS 6 software. This software is no longer maintained and therefore was not used here.

3. These effects can also be found as an interaction (Czech anthropomorphism. main effect: $\beta=.177$, interaction: $\beta=-.156$; Slovakia anthropomorphism main effect: $\beta=.157$, interaction: $\beta=-.252$ ). We presented them as separate samples for ease of interpretation.

\section{References}

Andersen, M. (2017). Predictive coding in agency detection. Religion, Brain \& Behavior, 36, 1-6. doi:10.3389/fpsyg.2011.00395

Atran, S., \& Norenzayan, A. (2004). Religion's evolutionary landscape: Counterintuition, committment, compassion, communion. Behavioral and Brain Sciences, 713-770. doi:10.1017/ S0140525X04000172

Baimel, A., McNamara, R. A., Purzycki, B. G., Willard, A. K., \& Norenzayan, A. (n.d.). How is mentalizing related to religious belief? A test of three models. Unpublished Manuscript.

Banerjee, K., \& Bloom, P. (2014). Why did this happen to me? Religious believers and non-believers teleological reasoning about life events. Cognition, 133, 277-303. http://doi.org/10.1016/j.cogni tion.2014.06.017

Baron-Cohen, S., \& Wheelwright, S. (2004). The empathy quotient: An investigation of adults with Asperger syndrome or high functioning autism, and normal sex differences. Journal of Autism and Developmental Disorders, 34, 163-175. doi:10.1023/B: JADD. 0000022607.19833 .00
Barrett, J. L. (2000). Exploring the natural foundations of religion. Trends in Cognitive Science, 4, 29-34. https://doi.org/10.1016/ S1364-6613(99)01419-9

Barrett, J. L. (2004). Why would anyone believe in God? Cognitive science of religion series. Walnut Creek, CA: AltaMira Press.

Barrett, J. L. (2007). Cognitive science of religion: What is it and why is it? Religion Compass, 1, 1-19. http://doi.org/https://doi.org/10. 1111/j.1749-8171.2007.00042.x

Barrett, J. L., \& Lanman, J. A. (2008). The science of religious beliefs. Religion, Brain \& Behavior, 38, 109-124. https://doi.org/10.1016/ j.religion.2008.01.007

Bloom, P. (2005). Descartes' Baby: How the Science of Child Development Explains What Makes Us Human. New York: Basic Books.

Boyer, P. (2001). Religion Explained. New York, NY: Basic Books.

Bulbulia, J. A. (2004). The cognitive and evolutionary psychology of religion. Biology and Philosophy, 19, 655-686. http://doi.org/ https://doi.org/10.1007/s10539-005-5568-6

Damasio, A. (1994). Descartes' error: Emotion, reason, and the human brain. New York: Putnam.

Epley, N., Akalis, S., Waytz, A., \& Cacioppo, J. T. (2008). Creating social connection through inferential reproduction: Loneliness and perceived agency in gadgets, gods, and greyhounds. Psychological Science, 19, 114-120. doi:10.1111/j.1467-9280.2008.02056.x

Epley, N., Waytz, A., Akalis, S., \& Cacioppo, J. T. (2008). When we need a Human: Motivational determinants of anthropomorphism. Social Cognition, 26, 143-155. doi:10.1521/soco.2008.26.2.143

Evans-Pritchard, E. E. (1937). Witchcraft, Oracles and Magic Among The Azande. Oxford, England: Clarendon Press.

Gervais, W. M., \& Henrich, J. (2010). The Zeus problem: Why representational content biases cannot explain faith in gods. Journal of Cognition and Culture, 10, 383-389. doi:10.1163/ $156853710 \times 531249$

Gervais, W. M., van Elk, M., Xygalatas, D., McKay, R. T., Aveyard, M. E., Buchtel, E. E., . . . Svedholm-Häkkinen, A. M. (2018). Analytic atheism: A cross-culturally weak and fickle phenomenon? Judgment and Decision Making, 13, 268-274. https://doi.org/10. 17605/OSF.IO/92R8X

Gervais, W. M., Willard, A. K., Norenzayan, A., \& Henrich, J. (2011). The cultural transmission of faith: Why natural intuitions and memory biases are necessary, but insufficient, to explain religious belief. Religion, Brain \& Behavior, 41, 389-400.

Guthrie, S. E. (1993). Faces in the clouds: A new theory of religion. New York: Oxford University Press.

Hackett, C., Connor, P., Stonawski, M., Skirbekk, V., Potancoková, M., \& Abel, G. (2015). The future of world religions: Population growth projections, 2010-2050. Washington, DC: Pew Research Center.Pew.

Hu, L. T., \& Bentler, P. M. (1999). Cutoff criteria for fit indexes in covariance structure analysis: Conventional criteria versus new alternatives. Structural Equation Modeling: a Multidisciplinary Journal, 6, 1-55. http://doi.org/10.1080/10705519909540118

Hume, D. (1779/1981). Dialogues concerning natural religion. Indianapolis, IN: Bobbs-Merrill.

Jack, A. I., Dawson, A. J., Begany, K. L., Leckie, R. L., Barry, K. P., Ciccia, A. H., \& Snyder, A. Z. (2013). fMRI reveals reciprocal inhibition between social and physical cognitive domains. 
NeuroImage, 66, 385-401. http://doi.org/10.1016/j.neuroimage. 2012.10.061

Järnefelt, E., Canfield, C. F., \& Kelemen, D. (2015). The divided mind of a disbeliever: Intuitive beliefs about nature as purposefully created among different groups of non-religious adults. Cognition, 140, 72-88. http://doi.org/10.1016/j.cognition.2015.02.005

Kay, A. C., Gaucher, D., McGregor, I., \& Nash, K. (2010). Religious belief as compensatory control. Personality and Social Psychology Review, 14, 37-48. doi:10.1177/1088868309353750

Kay, A. C., Whitson, J. A., Gaucher, D., \& Galinsky, A. D. (2009). Compensatory control: Achieving order through the mind, our institutions, and the heavens. Current Directions in Psychological Science, 18, 264-268. doi:10.1111/j.1467-8721.2009.01649.x

Kelemen, D. (1999). Function, goals and intention: children's teleological reasoning about objects. Trends in Cognitive Sciences, 3, 461-468. https://doi.org/10.1016/S1364-6613(99)01402-3

Kelemen, D. (2004). Are Children "Intuitive Theists?" Reasoning about purpose and design in nature. Psychological Science, 15, 295-301. http://doi.org/10.1111/j.0956-7976.2004.00672.x

Kelemen, D., \& Rosset, E. (2009). The human function compunction: Teleological explanation in adults. Cognition, 111, 138-143. doi: 10.1016/j.cognition.2009.01.001

Kline, R. B. (2011). Principles and practice of structural equation modeling. New York: The Guilford Press.

Laurin, K., \& Kay, A. C. (2017). The motivational underpinnings of belief in God. Advances in Experimental Social Psychology, 56, 201-257. doi:10.1016/bs.aesp.2017.02.004

Legare, C. H., \& Gelman, S. A. (2008). Bewitchment, biology, or both: The co-existence of natural and supernatural explanatory frameworks across development. Cognitive Science: A Multidisciplinary Journal, 32, 607-642. doi:10.1080/03640210802066766

Lindeman, M., Svedholm-Häkkinen, A. M., \& Lipsanen, J. (2015). Ontological confusions but not mentalizing abilities predict religious belief, paranormal belief, and belief in supernatural purpose. Cognition, 134, 63-76. doi:10.1016/j.cognition.2014.09.008

Lindeman, M., Svedholm, A. M., Takada, M., Lönnqvist, J. E., \& Verkasalo, M. (2011). Core knowledge confusions among university students. Science and Education, 20, 439-451. doi:10.1007/ s11191-009-9210-x

Lisdorf, A. (2007). "What's HIDD'n in the HADD?". Journal of Cognition and Culture, 7, 341-353. http://doi.org/10.1163/156853 707 X208549

Maij, D. L. R., van Harreveld, F., Gervais, W. M., Schrag, Y., Mohr, C., \& van Elk, M. (2017). Mentalizing skills do not differentiate believers from non-believers, but credibility enhancing displays do. PLoS ONE, 12, e0182764-e0182831. doi:10.1371/journal. pone. 0182764

Malinowski, B. (1954). Magic, science and religion. Boston, MA: Beacon Press.

Nosek, B. A., Alter, G., Banks, G. C., Borsboom, D., Bowman, S. D., Breckler, S. J., . . Yarkoni, T. (2015). Promoting an open research culture. Science, 348, 1422 LP-1425. doi:10.1126/science.aab2374

Purzycki, B. G., Apicella, C., Atkinson, Q. D., Cohen, E., McNamara, R. A., Willard, A. K., ... Henrich, J. (2016). Moralistic gods, supernatural punishment and the expansion of human sociality. Nature, 530, 327-10. http://doi.org/10.1038/nature16980
Rosseel, Y. (2012). lavaan: An R package for structural equation modeling. Journal of Statistical, 48, 1-36. doi:10.18637/jss.v048.i02

Sanchez, C., Sundermeier, B., Gray, K., \& Calin-Jageman, R. J. (2017). Direct replication of Gervais \& Norenzayan (2012): No evidence that analytic thinking decreases religious belief. PLOS ONE, 12, e0172636-8. http://doi.org/10.1371/journal.pone.0172636

Shariff, A. F., Willard, A. K., Andersen, T., \& Norenzayan, A. (2016). Religious priming a meta-analysis with a focus on prosociality. Personality and Social Psychology Review, 20, 27-48. http://doi. org/10.1177/1088868314568811

Stanovich, K. E. (1989). Implicit philosophies of mind: The dualism scale and its relation to religiosity and belief in extrasensory perception. Journal of Psychology, 123, 5. doi:10.1080/00223980. 1989.10542958

Tobacyk, J. J. (2004). A revised paranormal belief scale. The International Journal of Transpersonal Studies, 23. doi:10.24972/ijts. 2004.23.1.94

van Elk, M. V. (2013). Paranormal believers are more prone to illusory agency detection than skeptics. Consciousness and Cognition, 22, 1041-1046. doi:10.1016/j.concog.2013.07.004

van Elk, M., Matzke, D., Gronau, Q. F., Guan, M., Vandekerckhove, J., \& Wagenmakers, E.-J. (2015). Meta-analyses are no substitute for registered replications: A skeptical perspective on religious priming. Frontiers in Psychology, 6, 147-7. http://doi.org/10.3389/fpsyg. 2015.0136

Vonk, J., \& Pitzen, J. (2017). Believing in other minds: Accurate mentalizing does not predict religiosity. Personality and Individual Differences, 115, 70-76. doi:10.1016/j.paid.2016.06.008

Waytz, A., Cacioppo, J., \& Epley, N. (2010). Who sees human? The stability and importance of individual differences in anthropomorphism. Perspectives on Psychological Science, 5, 219-232. doi:10.1177/1745691610369336

Waytz, A., Morewedge, C. K., Epley, N., Monteleone, G., Gao, J.-H., \& Cacioppo, J. T. (2010). Making sense by making sentient: Effectance motivation increases anthropomorphism. Journal of Personality and Social Psychology, 99, 410-435. doi:10.1037/a0020240

Willard, A. K. (2017). Agency detection is unnecessary in the explanation of religious belief. Religion, Brain \& Behavior, 38, 1-3. doi: 10.1080/2153599X.2017.1387593

Willard, A. K., \& Cingl, L. (2017). Testing theories of secularization and religious belief in the Czech Republic and Slovakia. Evolution and Human Behavior, 38, 604-615. doi:10.1016/j.evolhumbehav. 2017.01 .002

Willard, A. K., \& Norenzayan, A. (2013). Cognitive biases explain religious belief, paranormal belief, and belief in life's purpose. Cognition, 129, 379-391. doi:10.1016/j.cognition.2013.07.016

Willard, A. K., \& Norenzayan, A. (2017). "Spiritual but not religious": Cognition, schizotypy, and conversion in alternative beliefs. Cognition, 165. doi:10.1016/j.cognition.2017.05.018

Wolf, E. J., Harrington, K. M., Clark, S. L., \& Miller, M. W. (2013). Sample size requirements for structural equation models: An evaluation of power, bias, and solution propriety. Educational and Psychological Measurement, 73, 913-934. doi:10.1177/ 0013164413495237

Handling Editor: Mark Brandt 